\title{
Noma in a child with congenital cardiopathy
}

\section{Mohamed Afellah ${ }^{1}$, Reda Hamdi ${ }^{1}$, Yousra Adoua ${ }^{1}$, Dounia Kamal', Mohamed Nourddine Elalami', Selma El Kadiri², Hanane Baybay², Zakia Douhi², Sara Elloudi ${ }^{2}$, Fatima-Zahra Mernissi ${ }^{2}$}

\author{
${ }^{1}$ Departement of Otorhinolaryngology, CHU Hassan II, Fez, Morocco, ${ }^{2}$ Department of Dermatology, CHU Hassan II, Fez, \\ Morocco
}

Corresponding author: Dr. Mohamed Afellah, E-mail: mohamed.afellah@gmail.com

\begin{abstract}
Noma is an invasive multibacterial infection that can lead to cutaneous necrosis and perforation of the orofacial tissue. Most reported cases are from the "Noma belt "that stretches from Senegal in the west to Ethiopia in the east. It is seen in young children under the age of six. Herein we report a case of a young Moroccan child with congenital cardiopathy referred to our emergency for cutaneous necroisis.At admission, the body temperature was $40^{\circ} \mathrm{C}$ and the patient was prostrated and dehydrated. Dermatological examination revealed a large 4-cms cutaneous necrosis extending from the mouth to the chin with loss of lowen jaw teeth. Blood and swab cultures from the gangrenous area revealed the growth of multiple aerobic and anaerobic bacteria. CT scan revealed mandibular necrosis.A triple antibiotherapy including ceftriaxone, metronidazole, and gentamycin was initiated along with intravenous rehydration, high protein diet, and oral doses of multivitamin supplements. Unfortunately after 8 days, the patient died from decompensation of his cardiopathy.
\end{abstract}

Key words: Noma; Morocco; Congenital cardiopathy

\section{INTRODUCTION}

Noma is an invasive multibacterial infection that can lead to cutaneous necrosis and perforation of the orofacial tissue. Most reported cases are from the " Noma belt " that's tretches from Senegal in the west to Ethiopia in the east. It isseen in young children under the age of six [1]. Herein we report a case of ayoun Moroccan child with congenital cardiopathy.

\section{CASE REPORT}

A 4 -year-old Moroccan male with congenital cardiopathy presented to emergency with a 4-cm ulcerative lesion on the chin. The onset started 8 days before withs welling. Initially, the lesions were vesicular during the last month. The parents attributed it to an insect bite and treated it with topical fusidic acid without improvement. He also reported abdominal pain, diarrhea, and weight loss. The parents reported that he was suffering from pain in his teeth and gingiva for the past month He was followed from his birth for interauricular communication with the persistence of arterial canal. His medical history was negative for any recurrent infection. At admission, the body temperature was $40^{\circ} \mathrm{C}$, pulse 120 per min, and respiratory rate 28 per min. Clinical examination revealed a prostrate and a dehydrated patient. The dermatological exam showed a large 4-cms cutaneous necrosis extending from the mouth to the chin (Figs. 1 and 2). Endobuccal examination revealed diffuse edema, halitosis with loss of lower jaw teeth. Cervical palpation revealed multiple cervical and submandibular adenopathy. Laboratory tests revealed a white cell count of $2.3 \times 109 / 1$ with $69 \%$ granulocytes and $30 \%$ lymphocytes, hemoglobinat $6.2 \mathrm{~g} / \mathrm{dl}$, and C-reactiveprotein $250 \mathrm{mg} / \mathrm{l}$. Blood testing showed functional kidney failure. An HIV test was negative. A chest X-ray showed a pulmonary infection. Blood and swab cultures from the gangrenous area revealed the growth of multiple aerobic and anaerobicbacteria. CT scan revealed mandibular necrosis. Clinical, biological, and radiological findings were compatible with

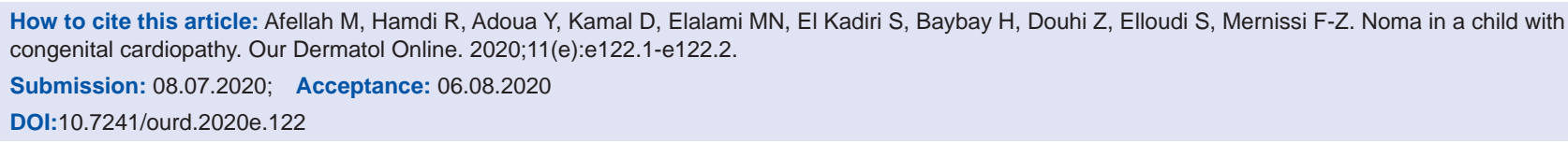




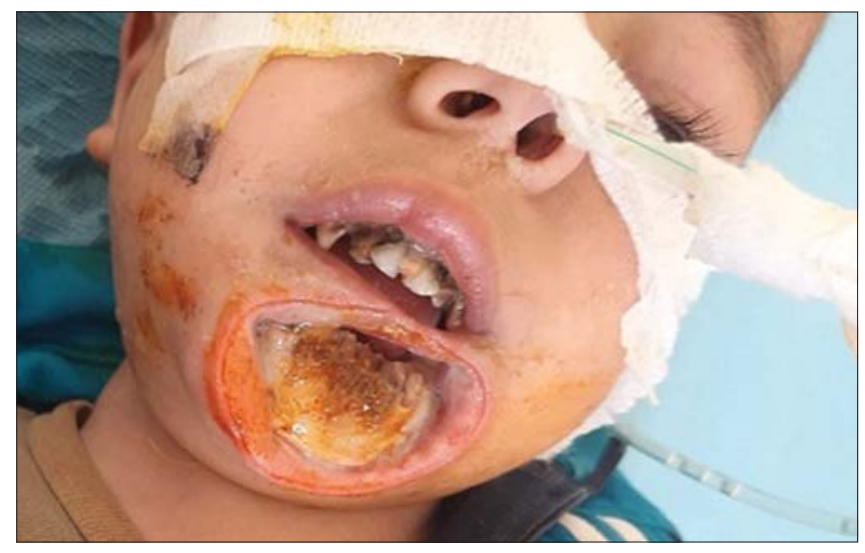

Figure 1: Large 4-cms cutaneous necrosis extending from the mouth to the chin.

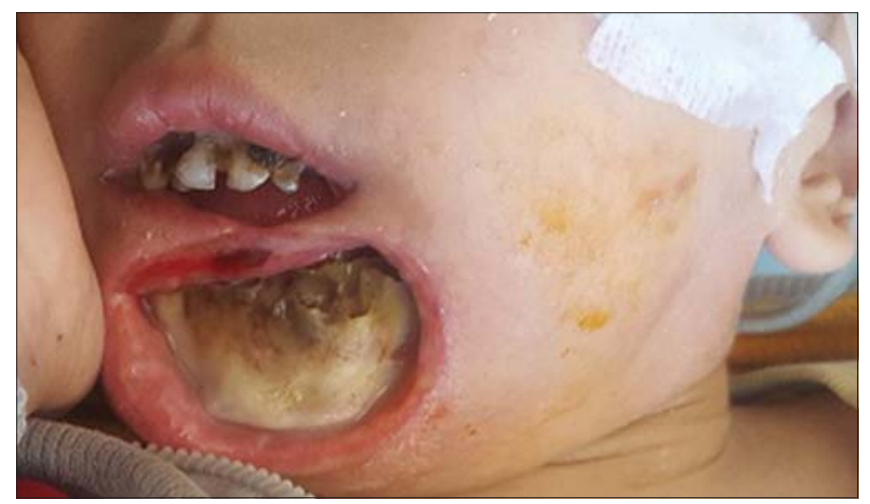

Figure 2: More close-up.

Noma. A triple antibiotherapy including ceftriaxone, metronidazole, and gentamycin was initiated along with intravenous rehydration, high proteindiet, and oral doses of multivitamin supplements. Unfortunately after 8 days, the patient died from decompensation of his cardiopathy.

\section{DISCUSSION}

Cancrum oris or widely know as noma is derived from the Greek which means to devour. It corresponds to acute gangrenous stomatitis that affects the oral mucosa, the labiomental, and or maxillary structures [1]. Most cases estimated by the World Health Organization are from Sub Saharan Africa specially from North Nigeria [2]. In Morocco, the cases were reported until 1993 [3]. Herein we report a sporadic case that occurring in a child with congenital cardiopathy. Noma has been known to be associated with multiple micro organisms including Fusobacterium necrophorum et Prevotella intermedia responsible for host tissues necrosis. This disease has to be distinguished from mycobacterial infection especially that we are an endemic country. Mucocutaneous leishmaniasis can lead to the destruction of mucous membranes [1]. Due to the rapid extension of the infection, an early diagnosis required to avoid tissue damage [2]. The antibiotic regimes recommended by the WHO is the combination of amoxicillin/ clavulanicacid or ampicillin associated with gentamycin, metronidazole, and topical chlorhexidine digluconate solution for mouth rinsing [4]. Luckily the mortality declined from $80-90 \%$ to $8-10 \%$ as a result of antibiotic use [1]. In our observation, we highlight the importance of rapid diagnosis and management of the underlying disease such us cardiopathy. In fact, as physicians we should alert that early antibiotic scan reverse the high mortality associated with the disease.

\section{CONCLUSION}

To the best of our knowledge, this is the first sporadic case of Nom a reported from Morocco since 1994 to alert physicians from the high mortality negative prognosis of the disease.

\section{Consent}

Examination of the patient was conducted according to the Declaration of Helsinki.

The authors certify that they have obtained all appropriate patient consent forms. In the form the patient(s) has/have given his/her/ their consent for his/her/their images and other clinical information to be reported in the journal. The patients understand that their names and initials will not be published and due efforts will be made to conceal their identity, but anonymity cannot be guaranteed.

\section{REFERENCES}

1. Zwetyenga N, See L-A, Szwebel J, Beuste M, Aragou M, Oeuvrard C, et al. Le Noma. Rev Stomatol Chir Maxillofac Chir Orale. 2015;116:261-79.

2. Madsen T, Medina C, Jespersen S, Wejse C, Hønge BL. Noma in an HIV infected patient in Guinea-Bissau: a case report. Infection. 2017;45:897-901.

3. Burki T. Facingnoma. Lancet Infec Dis. 2016;16:1231.

4. Lembo S, De Leonibus C, Francia MG, Lembo C, Ayala F. Cancrumoris in a boy with Down syndrome. J Am Acad Dermatol. 2011;64:1200-2.

Copyright by Mohamed Afellah, et al. This is an open access article distributed under the terms of the Creative Commons Attribution License, which permits unrestricted use, distribution, and reproduction in any medium, provided the original author and source are credited.

Source of Support: Nil, Conflict of Interest: None declared. 